\title{
Relasi Laki-laki dan Perempuan dalam Konstruksi Maskulinitas Jawa pada Lagu Dangdut Koplo
}

\author{
Chafit Ulya $^{1}$, Bagus Wahyu Setyawan ${ }^{2}$, Else Liliani ${ }^{3}$, Elen Inderasari ${ }^{4}$ \\ ${ }^{1}$ Universitas Sebelas Maret, Jalan Ir. Sutami 36-A, Kentingan, Surakarta, Jawa Tengah, Indonesia \\ ${ }^{2}$ Institut Agama Islam Negeri Tulungagung, Jalan Mayor Sujadi Timur, No. 46, Plosokandang, Kedungwaru, \\ Tulungagung, Jawa Timur, Indonesia \\ ${ }^{3}$ Universitas Negeri Yogyakarta, Jalan Colombo Yogyakarta No.1, Karang Malang, Kec. Depok, \\ Kab. Sleman, Yogyakarta, Indonesia \\ ${ }^{4}$ Institut Agama Islam Negeri Surakarta, Jalan Pandawa, Pucangan, Kec. Kartasura, Kab. Sukoharjo, \\ Jawa Tengah, Indonesia
}

chafi@@staff.uns.ac.id,bagusws93@gmail.com,else_l@uny.ac.id,inderasari85iain@gmail.com

\begin{abstract}
Modernisasi telah memberikan perubahan besar pada struktur kehidupan manusia, termasuk relasi laki-laki dan perempuan dalam kehidupan berkeluarga. Perubahan ini melahirkan konsep baru tentang maskulinitas, terutama yang ditemukan pada lagu dangdut koplo dari Jawa Timur. Maka, penelitian ini dilakukan untuk menjawab pertanyaan bagaimanakah bentuk relasi laki-laki dan perempuan dalam konstruksi maskulinitas Jawa pada lagu dangdut koplo? Metode deskriptif kualitatif digunakan dan memanfaatkan konsep maskulinitas sebagaimana dikemukakan oleh Janet Saltzman Chafetz. Chafetz menggambarkan tujuh wilayah maskulinitas tradisional pada budaya barat: fisik, fungsional, seksual, emosional, intelektual, interpersonal, dan sifat pribadi lain. Penulis artikel ini menyimpulkan bahwa lagu dangdut koplo Jawa menggambarkan relasi laki-laki dan perempuan dalam tiga dimensi maskulinitas: fungsional, emosional, dan intelektual. Dimensi fungsional memerankan laki-laki pada peran sebagai pencari nafkah; dan dimensi emosional sebagai memiliki ketenangan dan kematangan emosional yang tinggi; sedangkan dimensi intelektual menghadirkan sosok laki-laki dengan pemikiran yang logis, rasional, dan praktis.
\end{abstract}

Kata kunci: maskulinitas, maskulinitas Jawa, relasi laki-laki dan perempuan, lagu dangdut koplo

\section{Relations of Men and Women in the Construction of Javanese Masculinity in Dangdut Koplo Songs}

Modernization has contributed to major changes in the structure of human life, including relations between men and women within family life. This change gave rise to new concepts about masculinity, particularly those discovered in dangdut koplo songs of East Java. Hence, this research was conducted to answer the question of how is the form of relations between men and women in the construction of Javanese masculinity in dangdut koplo songs? A descriptive qualitative method was employed and utilized the concept of masculinity as put forth by Janet Saltzman Chafetz. Chafetz described seven areas of traditional masculinity in western culture: physical, functional, sexual, emotional, intellectual, interpersonal, and other personal characteristics. The authors of this article concluded that the Javanese dangdut koplo songs describe the relations between men and women through three dimensions of masculinity: functional, emotional, and intellectual. The functional dimension portrays men in the role of breadwinners; and the emotional dimension as having high emotional composure and maturity, while the intellectual dimension presents a male figure with logical, rational, and realistic thoughts.

Keywords: masculinity, Javanese masculinity, relations between men and women, dangdut koplo songs

Proses Review : 1 - 20 Mei 2021, Dinyatakan Lolos: 31 Mei 2021 


\section{PENDAHULUAN}

Modernisasi telah mengubah struktur kehidupan manusia, termasuk relasi antara laki-laki dan perempuan dalam kehidupan berkeluarga (Sudirana, 2019). Posisi laki-laki yang secara patriarki memiliki dominasi dalam kehidupan berumah tangga telah mengalami pergeseran. Ada hubungan relasional baru antara laki-laki dan perempuan dalam berbagai konteks kehidupan. Hubungan relasional baru ini terbentuk karena adanya sebuah perubahan pola piker, cara pandang, serta adanya suatu gaya hidup baru yang ditimbulkan oleh perkembangan zaman dan globalisasi. Akulturasi budaya semakin kental yang menyebabkan distorsi di berbagai sisi kehidupan yang pada akhirnya memunculkan suatu hubungan relasional baru.

Hubungan realional yang baru ini tampak dari berkurangnya kekerasan dalam rumah tangga yang dilakukan oleh laki-laki (Bustamante et al., 2019). Bahkan, hal ini pulalah yang memunculkan paradigma baru tentang konsep maskulinitas yang melibatkan laki-laki dalam usaha memerangi kekerasan gender terhadap perempuan (Joanpere \& Morlà, 2019). Laki-laki digambarkan sebagai sosok pengayom yang melindungi perempuan bukan sebagai sosok dominan dan diktator dalam sebuah hubungan rumah tangga.

Konsep maskulinitas ini selalu dipengaruhi oleh kebudayaan (Barker, 2012). Artinya, konsep maskulinitas selalu mengalami perkembangan seiring dengan dinamika perubahan dalam masyarakat. Oleh karena itu, ciri maskulinitas laki-laki pun dimanifestasikan dalam citra yang berubah-ubah. Pada masa lalu, sosok laki-laki sejati diidentikkan dengan sifat pantang menangis, selalu terlihat tegar, pemberani, kuat dan berotot, serta mampu menaklukkan hati banyak wanita. Bahkan, laki-laki sejati itu identik dengan rokok, alkohol, dan kekerasan (Donaldson, 1993). Namun demikian, pada tahun 1990an, maskulinitas tidak lagi ditentukan oleh gagasan tentang kekuasaan, kekuatan, agresivitas, tetapi lebih ditekankan pada kerentanan, pengabdian, dan kepedulian. Aspek-aspek inilah yang menjadi ciri tipe maskulitas baru (Prorokova, 2017).

Maskulinitas bukanlah sifat turunan yang dibawa sejak lahir. Maskulinitas merupakan konstruksi budaya yang keberadaannya akan sangat dipengaruhi oleh norma-norma yang berlaku di dalam lingkungannya. Proses konstruksi maskulinitas dilakukan selama masa kanak-kanak hingga dewasa (Albelda \& Infantes, 2017). Hal-hal yang berkaitan dengan kebiasaan, ritual, adat-istiadat masyarakat akan membentuk satu konsep tentang maskulinitas. Kondisi ini dapat ditemukan pada cara dan selera berpakaian, penampilan, aktivitas, cara menyelesaikan masalah, pola komunikasi, hingga pernak-pernik yang dikenakan (Vigorito \& Curry, 1998).
Berpijak pada dinamika konseptual tentang maskulinitas yang terus berkembang, upaya menggali dan menemukan paradigma baru tentang maskulinitas, utamanya dalam kaitannya dengan relasi laki-laki dan perempuan, merupakan isu yang selalu relevan untuk dijadikan bahan kajian. Salah satu objek yang menarik untuk meredefinisi konsep maskulinitas ini adalah lagu-lagu dangdut koplo, terutama yang ditulis oleh para pengarang laki-laki. Dalam kacamata kajian pemaknaan yang telah dilakukan, lagulagu dangdut koplo era 2010-an memiliki dimensi berbeda tentang konsep maskulinitas, dibandingkan dengan konsep maskulinitas tradisional yang dianut oleh sebagian masyarakat Jawa. Ada perubahan ciri maskulinitas yang ditandai dengan pergeseran dari simbol laki-laki yang mengayomi, mendominasi, dan menguasai, menjadi laki-laki yang mengedepankan kesabaran, rasa cinta, dan kesetiaan.

Dalam konsep maskulinitas tradisional masyarakat Jawa, laki-laki digambarkan dengan sosok yang rasional, bertubuh kuat, kasar, perkasa, pemberani, tegas, dan agresif (Seramasara, 2019). Sementara itu, perempuan diidentikkan dengan sosok yang lemah lembut, manja, penakut, dan penuh kasih sayang (Pranowo \& Susanti, 2020). Konsep maskulinitas tradisional menempatkan laki-laki menjadi sosok superior terhadap perempuan (Olson et al., 2013) dalam berbagai sendi kehidupan, baik domestik maupun publik. Hegemoni laki-laki atas perempuan ini juga dilegitimasi oleh nilai-nilai yang berlaku di masyarakat, baik nilai sosial, agama, hukum, dan sebagainya. Beberapa dogma yang tertanam pada masyarakat Jawa tentang superioritas laki-laki terhadap perempuan misalnya istilah 'swarga nunut neraka katut'. Ada juga istilah 'kanca wingking' yang menunjukkan peran domestik istri dengan tugas utama ' $3 \mathrm{M}$ ' - masak, macak, dan manak atau "4 ur"- dapur, pupur, kasur, dan sumur. Modernisasi mencoba mengoreksi konsep hegemoni laki-laki yang secara relasional menggeser ciri maskulinitas pada laki-laki.

Usaha menemukan paradigma baru tentang maskulinitas dalam musik atau lirik lagu bukan merupakan hal baru. Sudah banyak kajian yang menyinggung persoalan ini. Dalam satu kajian terhadap perkembangan topik dalam lagu gaya country tahun 1980-an hingga 2010-an, ditemukan bahwa aspek maskulinitas yang relatif konsisten diangkat dalam lagu gaya country berbicara tentang pekerjaan kaum lelaki dan kecenderungan heteroseksualitas (Leap, 2019).

Kajian tentang lirik lagu pop di negara Inggris juga menemukan perbedaan isi antara lirik lagu yang dinyanyikan perempuan dengan laki-laki. Lirik lagu yang dinyanyikan perempuan cenderung menggambarkan halhal pokok tentang nilai-nilai kebajikan, tentang inspirasi dan motivasi. Sebaliknya, lirik lagu yang dinyanyikan penyanyi laki-laki cenderung membahas konsep stereotip tentang maskulinitas remaja (Krause \& North, 2019). Hal 
yang sangat berbeda ditemukan pada lagu gaya rap yang di dalamnya masih didominasi oleh konsep maskulinitas laki-laki Afro-Amerika. Kekerasan, kehidupan glamor, dan hegemoni laki-laki Afro-Amerika menjadi ciri maskulinitas dalam lagu gaya rap (Oware, 2011). Bahkan, topik kekerasan mengalami peningkatan yang signifikan pada lagu gaya rap ini (Herd, 2009).

Melihat dinamika perubahan konsep maskulinitas dalam lirik-lirik lagu di atas, kajian tentang dimensi maskulinitas dalam lagu dangdut koplo ini merupakan sesuatu yang menarik untuk dikaji. Dalam catatan penulis, lirik-lirik lagu dangdut koplo memiliki ciri dan karakteristik unik dalam menyajikan persoalan maskulinitas. Ada perubahan paradigma dalam masyarakat tentang relasi laki-laki dan perempuan pada masyarakat Jawa dewasa ini yang direpresentasikan dalam lagu dangdut tersebut. Oleh karenanya, penelitian ini dilakukan untuk menjawab pertanyaan bagaimanakah bentuk relasi laki-laki dan perempuan dalam konstruksi maskulinitas Jawa pada lagu dangdut koplo?

Objek kajian dalam penelitian ini difokuskan pada lagulagu karangan grup Pendhoza. Pendhoza merupakan salah satu klub hip-hop Jawa yang berasal dari Jogjakarta. Seiring perkembangan waktu, lagu-lagu dari grup Pendhoza ini banyak dinyanyikan dengan irama dangdut koplo oleh para penyanyi wanita. Hal ini yang menjadi menarik untuk dikaji sehingga menimbulkan suatu sudut pandang baru tentang konsep maskulinitas. Lirik lagu yang diciptakan oleh seorang laki-laki ditujukan kepada seorang wanita, pada akhirnya popular dan tenar dinyanyikan oleh penyanyi wanita. Selain itu, dari sekian banyak lagu yang diciptakan oleh Pendhoza, diantaranya menjadi lagu-lagu yang dapat dikatakan hits dan terkenal sehingga kerap dinyanyikan oleh banyak masyarakat Jawa dari berbagai kalangan.

\section{METODE PENELITIAN}

Metode deskriptif kualitatif digunakan dan memanfaatkan konsep maskulinitas sebagaimana dikemukakan oleh Janet Saltzman Chafetz. Chafetz menggambarkan tujuh wilayah maskulinitas tradisional pada budaya barat: fisik, fungsional, seksual, emosional, intelektual, interpersonal, dan sifat pribadi lain (Chafetz, 1974). Data penelitian dikumpulkan dari lagu dangdut koplo yang dikarang oleh Pendhoza. Pengambilan sampel penelitian dilakukan dengan teknik purposive sampling. Teknik purposive sampling diarahkan pada lagu Pendhoza dengan judul Bojo Galak, Demi Kowe, Aku Cah Kerja, dan Digawe Penak (Bojo Galak 2). Beberapa lagu tersebut dipilih karena dianggap lebih bisa merepresentasikan data-data tentang tiga dimensi dalam konsep maskulinitas laki-laki Jawa yang baru. Data dianalisis dengan pendekatan analisis isi, yaitu teknik penelitian yang menarik simpulan dari teks ke dalam konteks pemakaiannya (Krippendorff, 2004).
Penelitian ini menghasilkan data berupa kata-kata tertulis (Taylor \& Bogdan, 1998). Data kemudian dianalisis dengan menggunakan model analisis interaktif yang terdiri atas pengumpulan data, reduksi data, penyajian data, dan verifikasi atau penarikan simpulan (Miles \& Huberman, 1994).

\section{ANALISIS DAN INTERPRETASI DATA}

Di dalam membahas relasi laki-laki dan perempuan dalam konstruksi maskulinitas pada lagu dangdut koplo ini, digunakan teori Janet Saltzman Chafetz. Dalam pandangan Chafetz, ada tujuh ciri maskulinitas pada diri laki-laki, yaitu (1) fisik: jantan, atletis, kuat, berani, tidak peduli terhadap penampilan dan proses penuaan; (2) fungsional: pencari nafkah bagi keluarga, pembela keluarga dari ancaman fisik; (3) seksual: agresif secara seksual, berpengalaman, status lajang dapat diterima; (4) emosional: tidak emosional, tabah, tidak pernah menangis; (5) intelektual: logikal, intelektual, rasional, objektif, praktis; (6) interpersonal: pemimpin, mendominasi, pendisiplin, mandiri, bebas individualis, menuntut; dan (7) sifat pribadi lain: berorientasi pada kesuksesan, ambisius, agresif, kompetitif, bangga, egois, bermoral, dapat dipercaya, tegas, tanpa hambatan, petualang (Chafetz, 1974). Di antara tujuh ciri maskulinitas tersebut, hanya ditemukan tiga ciri maskulinitas yang menggambarkan relasi laki-laki dan perempuan, yaitu ciri fungsional, emosional, dan intelektual. Berikut ini deskripsi lengkap tentang ketiga ciri maskulinitas tersebut.

\section{Dimensi Fungsional}

Secara fungsional, peran utama laki-laki adalah sebagai pencari nafkah, sedangkan istri sebagai pengelola keuangan (Nurlian; Darulay, 2008). Pada era modern, ada peran tambahan yang melekat pada sebagian perempuan sebagai penunjang ekonomi keluarga dengan bekerja atau menjalankan usaha secara mandiri di rumah (Putri \& Lestari, 2015). Meskipun biasanya, istri yang berperan ganda seperti ini cenderung tidak mengejar karier (Coltrane, 2004). Namun demikian, posisi ini tidak menjadikan fungsi utama laki-laki sebagai pencari nafkah gugur begitu saja.

Tanggung jawab laki-laki sebagai pencari nafkah bagi keluarga ini ditemukan pada lagu $A k u$ Cah Kerja dan Demi Kowe. Kedua lagu ini berkisah tentang perjuangan laki-laki yang rela merantau demi bisa membahagiakan pasangannya. Lagu Demi Kowe lebih mengedepankan komitmen dan kesetiaan laki-laki dalam memperjuangkan kebahagiaan hari depan bersama calon istrinya.

Aku lila adoh omah, adoh wong tuwa

Demi kowe ben supaya tetep mulya

Tresnaku 'ra bakal ilang senajan adoh paranku

Setiaku karo kowe tekan matiku 
Perjuangan tersebut akhirnya membuahkan hasil karena kekasihnya mau menantinya hingga kembali dan bersamasama membangun keluarga. Keyakinan dan kepercayaan kekasihnya tersebut dibalas dengan janji untuk menjaganya sampai mati. Kisah mereka pun berakhir dengan sebuah pernikahan.

Matur suwun wis gelem nampa aku

Sampun percaya karo janji janjiku

Bakal tak jaga tekaning patiku

Kanggoku awakmu kuwi harga diriku

Lagu Demi Kowe menggambarkan semangat juang seorang laki-laki demi bisa membahagiakan perempuan pujaan hatinya. Untuk itu, laki-laki rela berpisah dengan keluarga dan kekasihnya untuk bekerja. Semangat juang dalam mencari nafkah ini menggambarkan ciri maskulinitas pada dimensi fungsional yang kuat pada sosok laki-laki.

Situasi yang lebih pelik dikisahkan pada lagu $A k u$ Cah Kerja. Pada lagu ini, perjuangan suami mencari nafkah diuji oleh perasaan cemburu dan curiga istri. Hati si istri dibuat curiga, cemburu, dan khawatir akan perilaku suaminya yang mungkin saja berselingkuh dengan perempuan lain. Pada bagian awal, dilukiskan perasaan hati si istri pada masa awal ditinggal pergi.

Mas, yen pancen tresnaku iki

Mbok anggep ra ana gunane

Aku ra kuciwa lan aku ra lara

Menyikapi kecurigaan istrinya, sang suami mencoba meyakinkan istrinya bahwa kepergiannya tersebut benarbenar diniatkan untuk bekerja demi mencukupi kebutuhan keluarga. Suami berjanji tidak akan tergoda dengan wanita lain karena di dalam hatinya, hanya ada istrinya seorang. Kemudian pada baris terakhir, si suami menguatkan kembali niatnya pergi ke luar kota adalah amung golek rejeki (hanya mencari nafkah, tidak ada yang lain).

Dhik, tresnaku mung siji kowe

Langit bumi kang dadi seksine

Yen neng ati ra ana wanita liya

Kowe rasah sok mutusi,

Aku ra neng endi-endi

Aku lunga amung golek rejeki

Ini adalah gambaran tanggung jawab seorang lakilaki sebagai kepala keluarga. Keinginan suami untuk mencarikan nafkah yang layak untuk keluarga merupakan dorongan utama yang menyebabkannya rela berjauhan dengan istrinya. Sang suami menyadari bahwa mencari nafkah merupakan kewajibannya (dongakna lakuku ngayahi kewajibanku).
Aja kelara-lara lungaku ra teges cidra Apa meneh nganti mikir aku wes ora tresna Ya mung kowe sing tansah ana neng njero dada $R a$ ana tresna liya merga aku tansah setia Kudu percaya tresnaku iki mung siji kowe Wani sumpah mati neng ati ra ana liyane Janjiku tak buktekke ora mung ana lambe Tunggunen baliku bebrayan tekane sak lawase

Petikan komposisi musik rap di atas menjelaskan secara lengkap kegelisahan istrinya. Suami berharap istrinya memahami keadaan itu, mendoakan keselamatan suaminya, dan menunggu kepulangannya dengan sabar. Penjelasan suami ini pun mampu meredakan hati istrinya. Maka, pada bagian akhir lagu, si istri bisa memahami dan mengikhlaskan kepergian suaminya untuk bekerja. Tidak lupa, istri menitipkan pesan kepada suami agar selalu setia dan jangan sampai tergoda oleh wanita lain.

Mas, yen pancen kuwi karepmu

Aku ya mung tansah bisa nunggu

Tak kuatne atiku tanpa sliramu

Mas, nadyan kowe lunga kerja

Sing tak jaluk kowe tetep setia

Aja nganti kegudha wanita liya

Pada dasarnya, lagu Aku Cah Kerja ini tidak menunjukkan relasi baru antara laki-laki dan perempuan dalam kaitannya dengan konstruksi maskulinitas pada tataran fungsional. Bahkan, melalui lagu ini, Pendhoza justru menguatkan konsep maskulinitas tradisional yang membagi peran antara suami dan istri. Suami fokus pada pekerjaan produktif, sedangkan istri pada pekerjaan reproduktif (Widodo, 2009). Suami bekerja di luar rumah, sedangkan istri fokus pada pekerjaan di dalam rumah.

Namun demikian, lagu Aku Cah Kerja ini tidak menitikberatkan persoalan relasi laki-laki dan perempuan pada sektor ekonomi. Artinya, suami dan istri tidak sedang mempermasalahkan pembagian tugas dalam mencari nafkah. Persoalan yang dimunculkan pada lagu ini lebih didorong oleh keinginan istri untuk hidup bersama-sama. Sementara itu, pada sisi lain, suami berusaha mengupayakan kehidupan yang lebih baik bagi keluarga dengan mencoba peruntungan rejeki di tempat lain. Negosiasi antara suami dan istri pun terjadi untuk menjaga keselarasan hubungan mereka. Suami meyakinkan hati istrinya dengan berjanji akan tetap setia, tidak tergoda dengan perempuan lain, dan hanya fokus pada pekerjaannya. Istri pun menurunkan egonya dengan mengikhlaskan suaminya pergi dengan iringan doa dan pesan-pesan agar memegang janji yang telah disepakati.

Relasi inilah yang mempertunjukkan bagaimana hubungan suami-istri itu mesti dijalankan. Pasangan suami 
istri berbagi peran dalam tiga hal, yaitu pengambilan keputusan, pengelolaan keuangan, dan pengasuhan anak. Dalam menjalankan ketiga peran tersebut, pasangan suami istri Jawa lebih mengutamakan keselarasan hubungan sehingga ketiga peran tersebut dijalankan secara fleksibel (Putri \& Lestari, 2015). Pada lagu Aku Cah Kerja, upaya menjaga keselarasan hubungan tersebut menjadi hal yang sangat ditonjolkan oleh pasangan suami-istri dengan tetap mempertahankan peran fungsionalnya masing-masing. Demikian halnya upaya keras yang dilakukan oleh sosok laki-laki pada lagu Demi Kowe.

\section{Dimensi Emosional}

Secara emosional, laki-laki dicirikan dengan kepribadian yang tidak emosional, bersikap tabah, dan pantang menangis. Hal ini pulalah yang banyak ditemukan pada sosok laki-laki, utamanya dalam konteks hubungan relasional pasangan suami-istri. Dalam konteks kehidupan modern seperti saat ini, dominasi laki-laki dalam kehidupan berumah tangga memang sudah tidak terlalu kuat. Bahkan dalam beberapa kasus, justru perempuanlah yang menjadi lebih dominan. Pada lagu Bojo Galak, bukti dominasi dan superioritas perempuan ini dapat dibuktikan dan sekaligus kematangan emosional laki-laki yang menjadi penanda ciri maskulinitas pun mendapatkan ujian.

Lagu ini berisi curahan hati pengarang tentang istrinya yang pemarah. Sifat pemarah tersebut membuat istrinya menjadi sosok superior di dalam keluarga. Suami dipaksa untuk mengikuti aturan main istrinya, dan mau tidak mau suami pun rela melakukannya demi menjaga keutuhan rumah tangga. Ketenangan dalam menghadapi istri menandakan kematangan emosional kaum laki-laki.

Bait pertama lagu ini menceritakan keberserahan lakilaki terhadap nasibnya memiliki seorang istri yang galak. Istrinya tersebut digambarkan seneng muring (sering marah-marah) dan omongane sengak (kata-katanya menyakitkan). Namun demikian, sang suami mencoba untuk ikhlas menerima nasib tersebut. Kalimat ' $k u d u$ tak trima, bojoku pancen galak' (harus aku terima, istriku memang pemarah) menjadi penanda penjelasan sikap seorang suami yang memiliki kestabilan dan ketenangan emosional dalam menghadapi kemauan istrinya. Kestabilan emosi tersebut adalah representasi dari maskulinitas yang dimiliki oleh seorang lelaki atau suami terhadap sikap istrinya yang tidak menyenangkan.

saben dina rasane ora karuan ngrasake bojoku sing ra tau perhatian nanging piye maneh atiku wis kadung tresna senajan batinku ngampet ana njero dhadha

Tidak berbeda dengan bait pertama, bait kedua lagu ini berkisah curahan hati suami yang merasakan hari-harinya dipenuhi dengan hal yang tidak menyenangkan (saben dina rasane ora karuan).Suami tidak pernah mendapatkan perhatian dari istrinya apalagi dilayani selayaknya kepala keluarga. Sikap istrinya yang seperti itu menumbuhkan rasa kesal di dalam hatinya. Namun, rasa cinta yang telanjur tumbuh dan berkembang di dalam hatinya ternyata mampu mengalahkan semuanya.

Pada bait kedua tersebut tergambarkan sikap suami dalam menyikapi tindakan istri yang tidak perhatian dengan cara membesarkan rasa cintanya daripada luka batin yang dialami. Tersurat dalam lirik 'nanging piye maneh atiku wes kadung tresna senajan batinku ngampet ana njero dada' (tapi mau bagaimana lagi, hatiku sudah telanjur cinta, meskipun batinku menahan sesak di dada). Tindakan suami tersebut menandakan kematangan emosional yang tinggi. Suami mencoba mendominasi rasa cinta untuk menenangkan emosi daripada memikirkan luka di hatinya. Hal tersebut dapat dikategorikan dalam ciri-ciri maskulinitas yang dimiliki suami, yakni tidak emosional atau selalu tenang.

ya wis ben nduwe bojo sing galak ya wis ben sing omongane sengak seneng nggawe aku susah nanging aku wegah pisah

tak tanpa nganggo tulusing ati tak trima sliramu tekan saiki mungkin wes dadi jodhone senajan kahanane kaya ngene

Puncak dari kematangan emosional laki-laki tampak pada bagian refrain lagu. Kematangan emosional tersebut mengarah pada level religiusitas yang tinggi tentang jodoh, yakni keyakinan bahwa jodoh ada di tangan Tuhan. Menjalani hidup dengan jodoh yang sudah ditetapkan Tuhan termasuk sikap religius yang sangat penting dalam pandangan Islam (Thalib, 2015). Jadi, meskipun kehidupan rumah tangganya tidak berjalan harmonis, keyakinan terhadap jodoh sebagai takdir Tuhan menjadikan laki-laki cenderung ikhlas menjalaninya.

Jodoh tidak bisa semata-mata dilihat dari adanya persamaan karakteristik kepribadian pasangan, tetapi lebih dipengaruhi oleh bagaimana keduanya menjalani hubungan dalam satu ikatan (Zentner, 2005). Pada lagu Bojo Galak, laki-laki lebih memilih menikmati hubungan dengan istrinya, betapa pun beratnya, daripada berpisah (nanging aku wegah pisah). Paling jauh, laki-laki pergi keluar rumah untuk 'ngopi' atau nongkrong di warung kopi untuk sekadar melepaskan beban hidupnya sejenak.

\section{Kuat dilakoni yen ora kuat ditinggal ngopi Tetep cinta, senajan bojoku galak}

Dalam sebuah penelitian, tidak harmonisnya hubungan suami istri disebabkan oleh pekerjaan dankepuasan terhadap pernikahan. Pekerjaan menjadi ukuran yang penting bagi 
laki-laki, sedangkan istri lebih mengedepankan kepuasan (Sayer et al., 2011). Akan tetapi, dari dua faktor tersebut, pekerjaan (persoalan ekonomi) tidak menjadi faktor dominan penyebab perceraian (Eliason, 2012). Pada kasus lagu Bojo Galak, ketidakharmonisan hubungan pernikahan mereka bukan disebabkan oleh kedua alasan tersebut, melainkan karena karakter dan watak masing-masing, terutama istri. Suami menyadari bahwa watak istrinya memang galak, sehingga dia bisa menerimanya dengan sangat ikhlas. Bahkan, ketika dimarahi oleh istrinya, suami memilih untuk diam saja.

yen wes ngono aku mung isa meneng

tak jelasna malah mung gawe kowe sepaneng

di matamu aku iki ora tau bener

kabeh mbok salahna rumangsa wis paling pinter

Ini adalah satu dimensi maskulinitas yang unik pada sosok laki-laki. Pada satu sisi, laki-laki punya kekuatan dan kekuasaan terhadap perempuan, tetapi dia memilih mengalah untuk menghindari konflik. Hal ini diyakini oleh kesadaran pada hakikat pernikahan yang paling mendasar adalah adanya komitmen, bukan sekadar cinta (Stassen \& Bates, 2010). Dalam hal ini, laki-laki memiliki kesadaran yang besar tentang komitmen dalam pernikahan. Ini adalah dimensi maskulinitas pada laki-laki.

Lagu Bojo Galak merepresentasikan sikap laki-laki era modern dalam menjalani kehidupan rumah tangganya. Dari lagu ini, kita dapat mengambil nilai bahwa konsep maskulinitas telah mengalamipergeseran, dari maskulinitas tradisional dengan simbol laki-laki yang mengayomi, mendominasi, dan menguasai, menjadi laki-laki yang mengedepankan kesabaran, rasa cinta, dan kesetiaan demi menjaga keutuhan rumah tangganya.

Dalam banyak aspek, pergeseran ini terjadi. Fenomena terpilihnya pemimpin daerah perempuan menjadi bukti adanya peran dan partisipasi yang lebih besar pada perempuan di ruang publik (Dewi, 2017). Kepemimpinan publik ini pun secara tidak langsung berdampak pada perubahan kepemimpinan domestik dalam wilayah keluarga.

\section{Dimensi Intelektual}

Secara intelektual, maskulinitas dicirikan dengan sosok laki-laki yang berpikiran logis, rasional, objektif, dan praktis. Ciri-ciri ini juga tergambarkan dalam lagu dangdut koplo yang ditulis oleh Pendhoza, seperti yang ditemukan pada lagu Digawe Penak.

Lagu ini merupakan serial kedua dari lagu Bojo Galak yang berkisah tentang curahan hati seorang suami memiliki istri yang galak. Pada lagu Digawe Penak ini, ciri maskulinitas yang berdimensi intelektual tampak lebih ditonjolkan oleh pengarang. Melalui lagu ini, pengarang mengajak para pendengar untuk berpikir praktis, logis, dan rasional tentang nasib. Ketika sudah ditakdirkan berpasangan dengan seseorang, pilihan sikap yang bisa diambil adalah bersyukur dan menjalaninya dengan ikhlas. Pesan ini secara lugas tampak pada penggalan lirik berikut.

\section{Tetep syukuri wae \\ Trima apa enenge \\ Mungkin iki dalane \\ Kuwe sing dadi jodhone}

Cara berpikir praktis dan tidak ribet itu semakin kuat terasa pada bagian refrain lagu. Di sini sikap dan cara berpikir pengarang untuk menerima takdir yang telah ditetapkan Tuhan sangat terasa. Dalam pandangan pengarang, hidup hanya sekali, lebih baik dinikmati.

\section{Ra sah dipikir nduwe bojo sing galak \\ Urip mung sepisan kudu digawe penak \\ Kudu kuwat atine wani nanggung bebane \\ Kabeh dilakoni yen wis ngene dalane}

Penggalan lirik di atas semakin menunjukkan cara berpikir seorang laki-laki yang serba logis, praktis, dan rasional. Bagi kaum laki-laki, hari depan tidak perlu ditakutkan. Yang terpenting adalah menjalani dan menikmati hari ini dengan penuh rasa syukur dan keikhlasan. Dengan demikian, seberat apapun beban hidup yang dihadapi, semua itu tidak akan menjadikan seorang laki-laki patah semangat. Jika permasalahan hidup yang dihadapi sudah sangat berat, relaksasi sejenak dengan pergi "ngopi" atau ke tempat "karaoke". Hanya saja, aktivitas tersebut tidak mengurangi rasa cinta dan tanggung jawab terhadap keluarga.

Seorang laki-laki Jawa dalam berpikiran memang lebih mengedepankan logika daripada rasa. Hal tersebut sudah terpatri dalam diri laki-laki semenjak kecil. Contoh nyatanya adalah ketika anak laki-laki sedang berkelahi maka tidak selang waktu lama mereka dapat akur kembali. Hal yang berbeda terjadi pada anak perempuan yang membutuhkan waktu lama untuk memulihkan perasaan mereka pascaberkelahi atau berbeda pendapat dengan temannya. Akan tetapi, di era sekarang banyak laki-laki yang malah mengedepankan rasanya daripada logika, apalagi kalau berurusan dengan permasalahan cinta banyak laki-laki yang terbawa perasaan. Akibat dari fenomena tersebut maka label maskulinitas seorang lakilaki mulai memudar dan menurun karena sudah banyak yang terbawa perasaan. Melalui lagu Digawe Penak ini, pengarang menitipkan pesan kepada kaum laki-laki agar lebih mengedepankan logika daripada rasa.

Dari beberapa lagu yang sudah dianalisis di depan, dapat dirumuskan satu pandangan bahwa sosok lakilaki dalam konteks lagu dangdut koplo karya Pendhoza menyadarkan kembali tentang peran penting seorang laki-laki. Maskulinitas yang dibangun oleh masyarakat 
Jawa tergolong berbeda dengan konsep maskulinitas pada umumnya. Dalam pandangan Robert O'mochain, misalnya, apa yang terjadi pada sosok laki-laki dalam lagu Bojo Galak sudah pada tataran korban dari kekerasan dalam rumah tangga (O'mochain, 2018). Namun demikian, laki-laki justru menerima kenyataan itu dengan ikhlas.

Apa yang ditemukan dalam penelitian ini telah melampaui hasil yang didapatkan oleh Lonngi tentang kemarahan laki-laki dalam kaitannya dengan kekerasan terhadap perempuan (Lonngi, 2017). Kekerasan dalam rumah tangga sudah tidak lagi didominasi oleh laki-laki, tetapi keduanya bisa saja ikut berperan. Hanya saja, laki-laki Jawa dalam konteks lagu dangdut koplo tidak pernah memandang perlakuan istri itu sebagai sebuah kekerasan. Justru sebaliknya, hal ini adalah bentuk atau ekspresi lain dari rasa cinta istri yang layak dibalas dengan kebesaran hati. Hal inilah yang menghasilkan relasi unik antara lakilaki dan perempuan.

Globalisasi memang telah memberikan pengaruh terhadap konsep maskulinitas. Relasi baru antara lakilaki dan perempuan tercipta oleh adanya globalisasi ini (Bustamante et al., 2019). Munculnya fenomena feminitas secara tidak langsung pasti berimbas pada dinamika perubahan pada aspek maskulinitas. Karena bagaimanapun juga, globalisasi telah memberikan dampak besar bagi peningkatan kapabilitas dan kualitas hidup bagi perempuan (Gray et al., 2006).

Melalui lagu dangdut yang diciptakan oleh Pendhoza ini, terjalin konsep relasional yang unik antara laki-laki dan perempuan. Dimensi hubungan di antara keduanya tidak lagi kepada permasalahan kekerasan ataupun penindasan satu dengan lainnya, tetapi justru pada dimensi kesabaran, dimensi keikhlasan, bahkan dimensi kerelijiusan. Lagu ini tampaknya menjadi cermin atas perilaku dan nasib yang dialami oleh banyak kaum laki-laki di Jawa, khususnya, sehingga demam terhadap lagu dangdut koplo ini begitu cepat menjalar. Banyak kaum laki-laki seolah terwakili perasaannya melalui lirik-lirik lagu yang ditulis oleh Pendhoza ini. Oleh karenanya, lagu-lagu yang diciptakan Pendhoza selalu menjadi viral dan pada akhirnya dinyanyikan oleh banyak penyanyi lain dalam beragam kesempatan.

\section{SIMPULAN}

Lagu dangdut koplo yang ditulis oleh Pendhoza menunjukkan relasi laki-laki dan perempuan dalam tiga dimensi maskulinitas, yaitu fungsional, emosional, dan intelektual. Dimensi fungsional menempatkan laki-laki pada peran sebagai pencari nafkah. Dimensi emosional menempatkan laki-laki pada pribadi dengan ketenangan dan kematangan emosional yang tinggi. Sementara itu, dimensi intelektual menghadirkan sosok laki-laki dengan pemikiran yang logis, rasional, dan praktis. Ketiga dimensi ini dilihat dari relasi antara laki-laki dan perempuan. Lakilaki cenderung menempatkan diri sebagai pihak yang mengalah. Prinsip mengalah ini dijalankan semata-mata untuk menjaga keselarasan hubungan dengan pasangannya. Prinsip ini sejalan dengan pepatah Jawa, 'Wani ngalah, luhur wekasane'. Selain itu, keyakinan terhadap rezeki, jodoh, dan takdir yang sudah digariskan Tuhan juga ikut mempengaruhi munculnya dimensi baru tentang maskulinitas pada lagu dangdut koplo. Poin potensial untuk dikaji adalah munculnya bentuk realitas yang baru dari sisi maskulinitas pria karena adanya perubahan fungsi, peran, dan keadaan di era modern. Adanya pengaruh globalisasi dan kehidupan modern menjadikan peran antara laki-laki dan perempuan juga bergeser. Pergeseran-pergeseran ini apabila tidak disikapi dengan lapang dada dan positif maka akan menimbulkan suatu ketimpangan peran sehingga akan mengganggu keseimbangan dalam hubungan antara laki-laki dan perempuan.

\section{DAFTAR RUJUKAN}

Albelda, J. S., \& Infantes, A. T. (2017). Logic practices in the process of construction of masculinity of Valencian men: Street, risk, football and ark. Masculinities and Social Change. https://doi.org/10.17583/mcs.2017.1937

Barker, C. (2012). An Introduction to Cultural Studies. Cultural Studies Theory and Practice. https://doi. org/10.4135/9781452204734

Bustamante, C. M., Quintal López, R. I., \& Amarís Macías, M. (2019). La violencia Masculina en la Pareja como Proceso Relacional: Un Desafío de Superación Cultural. Masculinities \& Social Change, 8(3), 307-331. https://doi. org/10.17583/mcs.2019.3809

Chafetz, J. S. (1974). Masculine/Feminine or Human? An Overview of the Sociology of Sex Roles. In FE Peacock Publishers. https://doi.org/10.1093/sf/54.3.729

Coltrane, S. (2004). Elite careers and family commitment: It's (still) about gender. Annals of the American Academy of Political and Social Science, 596(1), 214-220. https:// doi.org/10.1177/0002716204268776

Dewi, K. H. (2017). Piety and Sexuality in a Public Sphere: Experiences of Javanese Muslim Women's Political Leadership. Asian Journal of Women's Studies, 23(3), 340-362. https://doi.org/10.1080/12259276.2017. 1352250

Donaldson, M. (1993). What is hegemonic masculinity? Theory and Society. https://doi.org/10.1007/BF00993540

Eliason, M. (2012). Lost jobs, broken marriages. Journal of Population Economics, 25, 1365-1397. https://doi. org/10.1007/s00148-011-0394-4 
Gray, M. M., Kittilson, M. C., \& Sandholtz, W. (2006). Women and globalization: A study of 180 countries, 19752000. International Organization, 60(2), 293-333. https:// doi.org/10.1017/S0020818306060176

Herd, D. (2009). Changing images of violence in Rap music lyrics: 1979-1997. Journal of Public Health Policy. https://doi.org/10.1057/jphp.2009.36

Joanpere, M., \& Morlà, T. (2019). New Alternative Masculinities, the Struggle within and for the Feminism in Higher Education. HSE Social and Education History. https://doi.org/10.17583/MCS.2019.3936

Krause, A. E., \& North, A. C. (2019). Pop music lyrics are related to the proportion of female recording artists: Analysis of the United Kingdom weekly top five song lyrics, 1960-2015. Psychology of Popular Media Culture. https://doi.org/10.1037/ppm0000174

Krippendorff, K. (2004). Content Analysis: An Introduction to Its Methodology (second edition). In $S A G E$ Publications. https://doi.org/10.1103/PhysRevB.31.3460

Leap, B. (2019). A New Type of (White) Provider: Shifting Masculinities in Mainstream Country Music from the 1980s to the 2010s. Rural Sociology. https://doi. org/10.1111/ruso. 12276

Lonngi, L. B. (2017). Analysis of male "anger" in the context of violence against women in order to design a framework for construction of responsibility. Masculinities and Social Change, 6(1), 39-61. https://doi.org/10.17583/ mcs.2017.1923

Miles, M., \& Huberman, A. (1994). Miles and Huberman Chapter 2. In Qualitative Data Analysis.

Nurlian; Darulay, H. (2008). Kesetaraan Gender Dalam Pembagian Kerja Pada Keluarga Petani Ladang (Studi Kasus Analisa Isu Gender Pada Keluarga Petani Ladang di Desa Cot Rambong, Kecamatan Kuala, Kabupaten Nagan Raya, NAD). Jurnal Harmoni Sosial, II(2), 78-82.

O'mochain, R. (2018). La violencia sexual dirigida a hombres en conflictos: Un reto para los estudios de género. Masculinities and Social Change, 7(1), 1-23. https://doi. org/10.17583/MCS.2018.2986

Olson, D., DeFrain, J., \& Skogrand, L. (2013). Marriages and Families: Intimacy, Diversity, and Strengths (8th ed.). McGraw-Hill Education.

Oware, M. (2011). Brotherly Love: Homosociality and Black Masculinity in Gangsta Rap Music. Journal of African American Studies. https://doi.org/10.1007/s12111010-9123-4
Pranowo, P., \& Susanti, R. (2020). Strata Sosial Masyarakat Jawa sebagai Bahasa Nonverbal Statis: Kajian Etnopragmatik. Aksara, 32(1), 135-158. https://doi. org/10.29255/aksara.v32i1.548.135-150

Prorokova, T. (2017). Between Vietnam and 9/11: Arnold Schwarzenegger and a New Type of Masculinity in Twins and Kindergarten Cop. Masculinities \& Social Change. https://doi.org/10.17583/mcs.2017.2195

Putri, D. P. K. P., \& Lestari, S. (2015). Pembagian Peran dalam Rumah Tangga pada Pasangan Suami Istri Jawa. Jurnal Penelitian Humaniora, 16(1), 72-85.

Sayer, L. C., England, P., Allison, P. D., \& Kangas, N. (2011). She left, he left: How employment and satisfaction affect women's and men's decisions to leave marriages. American Journal of Sociology, 116(6). https://doi. org/10.1086/658173

Seramasara, I. G. N. (2019). Wayang Sebagai Media Komunikasi Simbolik Perilaku Manusia Dalam Praktek Budaya Dan Agama Di Bali. Mudra Jurnal Seni Budaya, 34(1), 80-86. https://doi.org/10.31091/mudra.v34i1.640

Stassen, H., \& Bates, B. (2010). Constructing Marriage: Exploring Marriage as an Ideograph. Qualitative Research Reports in Communication, 11(1), 1-5. https://doi. org/10.1080/17459430903412848

Sudirana, I. W. (2019). Tradisi Versus Modern: Diskursus Pemahaman Istilah Tradisi dan Modern di Indonesia. Mudra Jurnal Seni Budaya, 34(1), 127-135. https://doi. org/10.31091/mudra.v34i1.647

Taylor, S. J., \& Bogdan, R. (1998). Introduction to Qualitative Research Methods (3rd ed.). John Wiley \& Sons.

Thalib, M. D. (2015). Takdir Dan Sunnatullah (Suatu Kajian Tafsir Maudhu'i). AL-ISHLAH: Jurnal Pendidikan Islam, 13(1), 28-38. https://doi.org/10.35905/ALISHLAH. V13I1.486

Vigorito, A. J., \& Curry, T. J. (1998). Marketing masculinity: Gender identity and popular magazines. Sex Roles. https://doi.org/10.1023/A:1018838102112

Widodo, S. (2009). Analisis peran perempuan dalam usahatani tembakau. Embryo, 6(2), 148-153. https://doi. org/ISSN 0216-0188

Zentner, M. R. (2005). Ideal mate personality concepts and compatibility in close relationships: A longitudinal analysis. Journal of Personality and Social Psychology, 89(2), 242256. https://doi.org/10.1037/0022-3514.89.2.242 


\section{Daftar Rekaman}

Pendhoza Official. (2018, 20 April). Pendhoza - Di Gawe Penak [Bojo Galak 2] (Official Lyric Video). Retrieved from https://www.youtube.com/watch?v=YZWJpufdP60

Pendhoza Official. (2019, 7 Januari). Pendhoza - Demi Kowe (Official Audio Lyric). Retrieved from https://www. youtube.com/watch? $\mathrm{v}=\mathrm{Nd}-\mathrm{wk} 6 \mathrm{ESG} 3 \mathrm{I}$

Open Swara Genta. (2017, 26 Oktober). Pendhoza - Bojo Galak (Official Video). Retrieved from https://www. youtube.com/watch?v=H8eH_XfjRpc

Open Swara Genta. (2017, 27 Oktober). Pendhoza - Aku Cah Kerjo (Official Video). Retrieved from https://www. youtube.com/watch?v=wmPi76KUlvU 